\title{
Increased Bolus Volume Effect on Delayed Pharyngeal Swallowing Response in Post-stroke Oropharyngeal Dysphagia: A Pilot Study
}

Jin-Woo Park, MD, PhD, Gyu-Jeong Sim, MD, Dong-Chan Yang, MD, Kyoung-Hwan Lee, MD, Ji-Hea Chang, MD, Ki-Yeun Nam, MD, Ho-Jun Lee, MD, PhD, Bum-Sun Kwon, MD, PhD

Department of Physical Medicine and Rehabilitation, Dongguk University Ilsan Hospital, Goyang, Korea

\begin{abstract}
Objective To confirm a relationship between the pharyngeal response and bolus volume, and examine whether increasing the fluid bolus volume can improve penetration and aspiration for stroke dysphagic patients.

Methods Ten stroke patients with a delayed pharyngeal response problem confirmed by a videofluoroscopic swallowing study (VFSS) were enrolled. Each subject completed two swallows each of $2 \mathrm{~mL}, 5 \mathrm{~mL}$, and $10 \mathrm{~mL}$ of barium liquid thinned with water. The pharyngeal delay time (PDT) and penetration-aspiration scale (PAS) were measured and the changes among the different volumes were analyzed.

Results PDTs were shortened significantly when $5 \mathrm{~mL}$ and $10 \mathrm{~mL}$ of thin barium were swallowed compared to 2 $\mathrm{mL}$. However, there was no significant difference in PAS as the bolus volume increased.

Conclusion The increased fluid bolus volume reduced the pharyngeal delay time, but did not affect the penetration and aspiration status.
\end{abstract}

Keywords Deglutition disorders, Stroke, Reaction time, Respiratory aspiration, Fluoroscopy

\section{INTRODUCTION}

During swallowing, delayed pharyngeal swallowing occurs when the head of the bolus enters the pharynx and the pharyngeal swallow is not triggered within $0.4-0.5$ seconds, commonly indicated by laryngeal elevation when being discussed in the context of the rest of the pharyngeal swallow $[1,2]$. The issue has been commonly found among a large number of dysphagic patients, particularly those who are neurologically impaired, such as stroke patients $[3,4]$. If the pharyngeal swallow has not been initiated as the liquid passes the tongue base, there

Received April 15, 2016; Accepted July 5, 2016

Corresponding author: Gyu-Jeong Sim

Department of Physical Medicine and Rehabilitation, Dongguk University Ilsan Hospital, 27 Dongguk-ro, Ilsandong-gu, Goyang 10326, Korea. Tel: +8231-961-7465, Fax: +82-31-961-7488, E-mail: skjoct09@gmail.com

ORCID: Jin-Woo Park (http://orcid.org/0000-0003-4989-2575); Gyu-Jeong Sim (http://orcid.org/0000-0003-4083-4934); Dong-Chan Yang (http://orcid. org/0000-0001-7733-4066); Kyoung-Hwan Lee (http://orcid.org/0000-0002-8720-3315); Jihea Chang (http://orcid.org/0000-0003-0115-0492); Kiyeun Nam (http://orcid.org/0000-0001-6932-6541); Ho-Jun Lee (http://orcid.org/0000-0002-1997-2593); Bum Sun Kwon (http://orcid.org/0000-0001-7755435X).

(c) This is an open-access article distributed under the terms of the Creative Commons Attribution Non-Commercial License (http://creativecommons.org/ licenses/by-nc/4.0) which permits unrestricted noncommercial use, distribution, and reproduction in any medium, provided the original work is properly cited. Copyright $\odot 2016$ by Korean Academy of Rehabilitation Medicine 
is an increased risk of the liquid entering the opened airway before the pharyngeal swallow has been activated $[1,5]$. To enhance the pharyngeal response, various therapeutic attempts using chemical, mechanical, or electrical stimuli have been conducted. However, the effect of these methods is still controversial [6].

Meanwhile, Lazarus et al. [7] reported in their study that when a greater bolus volume is provided, the pharyngeal response occurs sooner. This result strongly suggested a probability of treating oropharyngeal dysphagia by modifying the bolus volume. Researchers of this study hypothesized that if there were an advance in the pharyngeal response as the bolus volume increased, patients with oropharyngeal dysphagia would have improved symptoms (penetration, aspiration) by increasing swallowing volume. If an improvement were to be confirmed, the method could be considered a new type of treatment or a compensatory method. So, prior to initiating systematic, larger-scale study for proving its therapeutic validity, this pilot study was conducted to confirm a relationship between the pharyngeal response and the bolus volume for stroke dysphagic patients and examine whether increasing the fluid bolus volume might improve symptoms.

\section{MATERIALS AND METHODS}

\section{Subjects}

Post-stroke patients who were referred to our stroke rehabilitation center from November 2013 to October 2014 were enrolled according to the following inclusion criteria: (1) stroke revealed by CT or MRI scan and (2) oropharyngeal dysphagia with a delayed pharyngeal response confirmed by a videofluoroscopic swallowing study (VFSS) using pharyngeal delay time (PDT) which takes 0.5 seconds or more. The cutoff value ( 0.5 seconds) was taken from a previous study $[1,2]$. Exclusion criteria were as follows: (1) prior history of neurologic disease, head and neck injuries, or gastroenterological dysfunction that might affect the swallowing function, (2) taking medication of which might affect swallowing, including antidepressants, (3) severe consciousness impairment that might interrupt the examination, and (4) cases that PDT could not be measured by problems in the oral phase, such as severe impairment in tongue control followed by absence of pharyngeal swallowing trigger.

This study was approved by the Institutional Review
Board and informed consent was obtained from every patient.

\section{Videofluoroscopic swallowing study}

Patients were seated upright and a 1.5-m distance from the X-ray tube (Sonialvision-100; Shimadzu Corporation, Kyoto, Japan) to the head was maintained. Each subject completed two swallows of each volume: $2 \mathrm{~mL}, 5 \mathrm{~mL}$, and $10 \mathrm{~mL}$, of barium liquid thinned with water sequentially administered by syringe. A digital picture archiving and communication system (PACS) directly captured the lateral view of the videofluoroscopic images. The capture rate was 30 frames per second and the frame size was $1021 \times 1021$ pixels.

\section{Outcome measures}

PDT and the penetration-aspiration scale (PAS) were determined after observing the entire swallowing action several times in real time and by using frame-by-frame analysis by one expert physician in a blind manner. PDT is interval from the time the bolus head reaches the point at which the ramus of the mandible crosses the base of the tongue until onset of laryngeal elevation, indicating the beginning of the pharyngeal swallow [1]. The mean value for each two swallowing trials was used. PAS is an 8-point clinical scale for rating penetration and aspiration. The severity of the rating depends on the perceived depth of the entry of food or fluid material into the airway and clearance of the material from the airway [8]. The mean value for every two swallowing trials was also calculated.

\section{Statistical analysis}

At first, the Kruskal-Wallis test was executed to compare the outcomes (PDT and PAS) of each non-parametric variable $(2 \mathrm{~mL}, 5 \mathrm{~mL}$, and $10 \mathrm{~mL})$. If the results indicated statistical significance, a post-hoc Wilcoxon signed-rank test was used to compare the outcomes between every two of the three variables using SPSS ver. 12.0 (SPSS Inc., Chicago, IL, USA). Statistical significance was attained when a p-value was less than 0.05 for Kruskal-Wallis test and less than 0.016 for Wilcoxon signed-rank test applying Bonferroni adjustment. 


\section{RESULTS}

Ten post-stroke patients with oropharyngeal dysphagia were eligible for this study. The average age of participants was $66.8 \pm 8.5$ years ( 6 men and 4 women). Four of the 10 patients had experienced a hemorrhagic stroke, and 6 patients had experienced an ischemic stroke. Two had cortical lesions, 4 had subcortical lesions, 1 had a brainstem stroke, and the other 3 had mixed locations. Five patients ate a normal diet and had not been engaged in any dysphagia training program thus far. Four patients ate a modified diet and 1 patient practices in non-oral nutrition; these 5 patients were treated with our oropharyngeal training program. None of the participants had a history of aspiration pneumonia or tracheostomy. The demographics and general characteristics of all participants are described in Table 1, and PDT and PAS of each subject is described in Table 2 .

Kruskal-Wallis test exhibited a significant relationship between PDT of each non-parametric variable $(\mathrm{p}=0.006)$.

Table 1. Demographics and general characteristics of the participants in the study

\begin{tabular}{|c|c|c|c|c|c|}
\hline Subject no. & Sex/age (yr) & $\begin{array}{c}\text { Stroke duration } \\
\text { (mo) }\end{array}$ & MMSE & DOSS & Stroke \\
\hline 1 & $\mathrm{~F} / 64$ & 9 & 27 & 5 & Cortical \\
\hline 2 & $\mathrm{~F} / 68$ & 11 & 26 & 5 & Subcortical \\
\hline 3 & $\mathrm{M} / 71$ & 1 & 18 & 4 & Subcortical \\
\hline 4 & $\mathrm{M} / 56$ & 12 & 27 & 4 & Subcortical \\
\hline 5 & $\mathrm{~F} / 79$ & 12 & 25 & 5 & Brainstem \\
\hline 6 & $\mathrm{M} / 53$ & 1 & 27 & 3 & Subcortical \\
\hline 7 & $\mathrm{M} / 59$ & 13 & 26 & 5 & Mixed \\
\hline 8 & $\mathrm{M} / 74$ & 1 & 6 & 1 & Mixed \\
\hline 9 & $\mathrm{M} / 71$ & 1 & 20 & 5 & Cortical \\
\hline 10 & $\mathrm{~F} / 73$ & 3 & 22 & 2 & Mixed \\
\hline
\end{tabular}

MMSE, Mini-Mental Status Examination; DOSS, Dysphagia Outcome and Severity Scale (7-point scale developed to systematically rate the functional severity of dysphagia based on an objective assessment and make recommendations for diet level, independence level, and type of nutrition. Level 5 indicates the patients may require a certain type of diet consistency restriction (our subjects had been eating tolerable diet with fluid caution). Level 3-4 indicates the patients require one or more consistency restriction. Level 1-2 are non-oral nutrition necessity states [21].

Table 2. PDT and PAS of each subject in different bolus volume

\begin{tabular}{|c|c|c|c|c|c|c|}
\hline \multirow{2}{*}{ Subject no. } & \multicolumn{3}{|c|}{ PDT } & \multicolumn{3}{|c|}{ PAS } \\
\hline & $2 \mathrm{~mL}$ & $5 \mathrm{~mL}$ & $10 \mathrm{~mL}$ & $2 \mathrm{~mL}$ & $5 \mathrm{~mL}$ & $10 \mathrm{~mL}$ \\
\hline 1 & 0.93 & 0.36 & 0.43 & 1 & 1 & 1 \\
\hline 2 & 1.50 & 0.86 & 0.57 & 1 & 2 & 2 \\
\hline 3 & 1.07 & 0.64 & 0.14 & 4 & 5 & 1 \\
\hline 4 & 0.53 & 0.14 & 0.14 & 2 & 5 & 2 \\
\hline 5 & 1.00 & 0.86 & 0.29 & 1 & 2 & 1 \\
\hline 6 & 2.14 & 0.43 & 0.29 & 7 & 5 & 8 \\
\hline 7 & 0.64 & 0.14 & 0.22 & 1 & 2 & 2 \\
\hline 8 & 1.29 & 1.29 & 1.29 & 8 & 8 & 8 \\
\hline 9 & 0.50 & 0.07 & 0.14 & 2 & 2 & 2 \\
\hline 10 & 0.57 & 0.14 & 0.07 & 4 & 1 & 1 \\
\hline Mean & 1.02 & 0.49 & 0.36 & 3.1 & 3.3 & 2.8 \\
\hline
\end{tabular}

PDT, pharyngeal delay time; PAS, penetration-aspiration scale. 


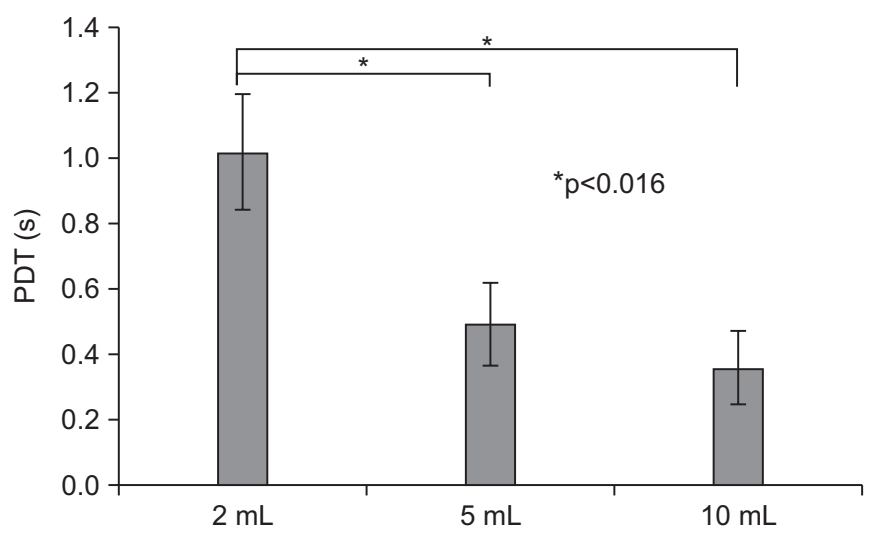

Fig. 1. The graph shows changes in pharyngeal delay time (PDT) according to bolus volume changes. PDTs are shortened significantly when $5 \mathrm{~mL}$ or $10 \mathrm{~mL}$ thin barium are swallowed, as compared to $2 \mathrm{~mL}$.

Following the post-hoc Wilcoxon signed-rank test it was revealed that PDTs were shortened significantly when 5 $\mathrm{mL}$ or $10 \mathrm{~mL}$ of thin barium was swallowed compared to $2 \mathrm{~mL}$ ( $\mathrm{p}=0.008,2 \mathrm{~mL}$ vs. $5 \mathrm{~mL}$; $\mathrm{p}=0.008,2 \mathrm{~mL}$ vs. $10 \mathrm{~mL}$; and $\mathrm{p}=0.159,5 \mathrm{~mL}$ vs. $10 \mathrm{~mL}$ ). The mean value was 1.02 seconds at $2 \mathrm{~mL}, 0.49$ seconds at $5 \mathrm{~mL}$, and $0.36 \mathrm{sec}$ onds at $10 \mathrm{~mL}$ (Fig. 1). However, there was no significant relationship between PAS and bolus volume $(\mathrm{p}=0.677$, Kruskal-Wallis). The mean value was 3.1 at $2 \mathrm{~mL}, 3.3$ at 5 $\mathrm{mL}, 2.8$ at $10 \mathrm{~mL}$ (Fig. 2). Bolus volume change, therefore, could not improve penetration or aspiration.

\section{DISCUSSION}

Lazarus et al. [7], and Bisch et al. [9] carried out their study with $2 \mathrm{~mL}, 5 \mathrm{~mL}$, and $10 \mathrm{~mL}$ of fluid, and administered it to stroke patients using VFSS to check PDT, determining that PDT got shorter when an increased bolus volume was given. However, Oommen et al. [10] did not find any significant results using $5 \mathrm{~mL}$ and $10 \mathrm{~mL}$ of fluid with healthy subjects or stroke patients when investigating stage transit duration, which led to controversy. Though there have been many other reports dealing with changes of various temporal measures of the swallow according to bolus volume using VFSS, manometry, acoustic signal and some others, few researchers have investigated the pharyngeal response, and most subjects were normal volunteers [11-17].

In the present study, stroke patients were asked to swallow $2 \mathrm{~mL}, 5 \mathrm{~mL}$, and $10 \mathrm{~mL}$ of fluid and confirm again

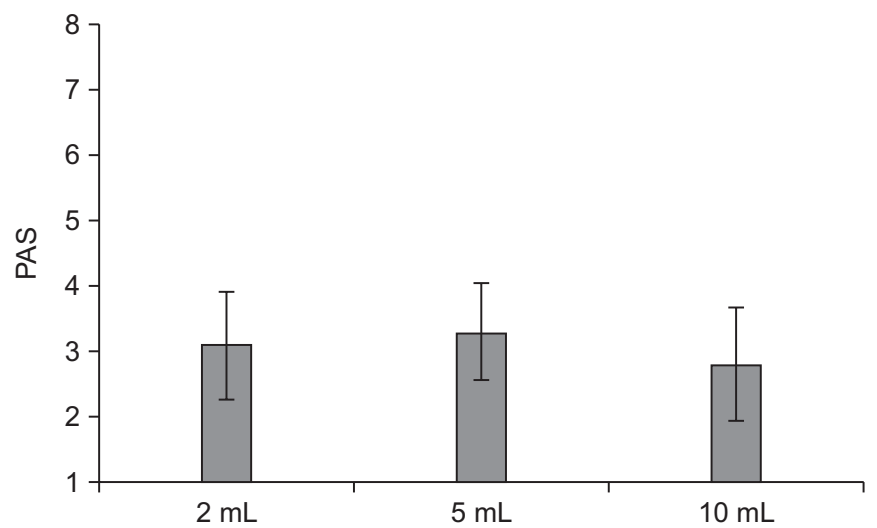

Fig. 2. The graph shows changes in the penetration-aspiration scale (PAS) according to bolus volume changes. There is no significant relationship between PAS and bolus volume.

that, if fluid bolus volume increased, there was a reduction in the pharyngeal response time. As noted in previous studies, researchers of this study hypothesize this is due to an increased sensory input in the oropharynx from the larger bolus volume $[6,7,9,18]$.

In an attempt to modify oropharyngeal dysphagia with pharyngeal response delay, several trials have suggested various techniques including chemical, mechanical, or electrical modifications. Most of the stimuli described as swallow sensory stimulants are integrated by receptors of the multimodal transient receptor potential channel family, mostly expressed in the sensory nerves. Enhancing the sensory stimuli may increase the sensory input to the swallowing center of the brain stem, thus triggering the swallow response earlier and protecting the airway. Moreover, sensory stimuli may promote brain plasticity, facilitating the recovery of deglutition. However, despite these theoretical bases, a definite effect of these methods is still controversial $[6,19]$.

So far, researchers of this study have not found any reports using bolus volume modification as a strategy for treating oropharyngeal dysphagia patients with delayed pharyngeal swallowing. As hypothesized, that the difference was related to an increase in mechanical sensory input, it was expected that the increased bolus volume would decrease the aspiration tendency. However, it was determined that increased fluid bolus volume did not actually decrease it.

Stroke dysphagic patients generally have an oral phase, pharyngeal motility, and coordination problems in ad- 
dition to the pharyngeal response delay [1]. Even if the pharyngeal response delay is improved with an increased bolus volume, problems such as premature bolus loss, decreased laryngeal elevation, and post-swallowing residue will remain. Especially, pharyngeal residue which would increase due to swallowing larger bolus volumes and cause aspiration by overflow from the pharyngeal reservoirs (vallecular or piriformis sinus) during or even after swallowing. Actually, one of the participants who had decreased pharyngeal contraction, showed not only improvement in pharyngeal response but also an increase of the residue without alteration of PAS. So, there could be an increased possibility of delayed aspiration. For these reasons, while our study does show that the increased bolus volume shortens the response delay, the increased bolus volume does not seem to be very helpful in improving penetration and aspiration.

Patients only having a pharyngeal response delay were not investigated. Additionally, all variables, which could influence outcomes, were not controlled for, such as a brain lesion and severity of dysphagia. Previous studies have demonstrated different patterns of dysphagia according to the stroke lesion type. They suggested dysphagia patterns could be classified by a supratentorial and infratentorial lesion and moreover, a supratentorial lesion presents different dysphagia patterns between the cortical and subcortical areas [20]. A relatively small sample size is a limitation, too. These problems were also seen in previous studies and if a future study is undertaken with excluding these limitations, more conclusive and meaningful results could be reached.

The increased fluid bolus volume shortened the pharyngeal delay time, but did not affect the patients' penetration and aspiration status. It is difficult to determine whether it could be used as a treatment option in stroke dysphagic patients from the current results. However as a pilot study, this study again showed a probability to modify swallowing problems by increasing volume. It can also provide useful information for future studies.

\section{CONFLICT OF INTEREST}

No potential conflict of interest relevant to this article was reported.

\section{REFERENCES}

1. Logemann JA. Evaluation and treatment of swallowing disorders. 2nd ed. Austin: Pro-ED; 1998. p. 77-113, 307-14.

2. Kim Y, McCullough GH, Asp CW. Temporal measurements of pharyngeal swallowing in normal populations. Dysphagia 2005;20:290-6.

3. Veis SL, Logemann JA. Swallowing disorders in persons with cerebrovascular accident. Arch Phys Med Rehabil 1985;66:372-5.

4. Mann G, Hankey GJ, Cameron D. Swallowing function after stroke: prognosis and prognostic factors at 6 months. Stroke 1999;30:744-8.

5. Perlman AL, Booth BM, Grayhack JP. Videofluoroscopic predictors of aspiration in patients with oropharyngeal dysphagia. Dysphagia 1994;9:90-5.

6. Rofes L, Cola PC, Clave P. The effects of sensory stimulation on neurogenic oropharyngeal dysphagia. J Gastroenterol Hepatol Res 2014;3:1066-72.

7. Lazarus CL, Logemann JA, Rademaker AW, Kahrilas PJ, Pajak T, Lazar R, et al. Effects of bolus volume, viscosity, and repeated swallows in nonstroke subjects and stroke patients. Arch Phys Med Rehabil 1993; 74:1066-70.

8. Rosenbek JC, Robbins JA, Roecker EB, Coyle JL, Wood JL. A penetration-aspiration scale. Dysphagia 1996; 11:93-8.

9. Bisch EM, Logemann JA, Rademaker AW, Kahrilas PJ, Lazarus CL. Pharyngeal effects of bolus volume, viscosity, and temperature in patients with dysphagia resulting from neurologic impairment and in normal subjects. J Speech Hear Res 1994;37:1041-59.

10. Oommen ER, Kim Y, McCullough G. Stage transition and laryngeal closure in poststroke patients with dysphagia. Dysphagia 2011;26:318-23.

11. Dantas RO, Kern MK, Massey BT, Dodds WJ, Kahrilas PJ, Brasseur JG, et al. Effect of swallowed bolus variables on oral and pharyngeal phases of swallowing. Am J Physiol 1990;258(5 Pt 1):G675-81.

12. Sible E, Perlman AL, He X. Effects of age, gender, bolus volume and viscosity on acoustic signals of normal swallowing. Turk J Phys Med Rehab 2007;53:94-9.

13. Gumbley F, Huckabee ML, Doeltgen SH, Witte U, Moran C. Effects of bolus volume on pharyngeal contact pressure during normal swallowing. Dysphagia 
2008;23:280-5.

14. Hoffman MR, Ciucci MR, Mielens JD, Jiang JJ, McCulloch TM. Pharyngeal swallow adaptations to bolus volume measured with high-resolution manometry. Laryngoscope 2010;120:2367-73.

15. Kahrilas PJ, Lin S, Chen J, Logemann JA. Oropharyngeal accommodation to swallow volume. Gastroenterology 1996;111:297-306.

16. Kahrilas PJ, Logemann JA. Volume accommodation during swallowing. Dysphagia 1993;8:259-65.

17. Lin T, Xu G, Dou Z, Lan Y, Yu F, Jiang L. Effect of bolus volume on pharyngeal swallowing assessed by highresolution manometry. Physiol Behav 2014;128:46-51.

18. Logemann JA. Preswallow sensory input: its potential importance to dysphagic patients and normal individuals. Dysphagia 1996;11:9-10.

19. Teismann IK, Steinstrater O, Warnecke T, Suntrup S, Ringelstein EB, Pantev C, et al. Tactile thermal oral stimulation increases the cortical representation of swallowing. BMC Neurosci 2009;10:71.

20. Lee SJ, Lee KW, Kim SB, Lee JH, Park MK. Voluntary cough and swallowing function characteristics of acute stroke patients based on lesion type. Arch Phys Med Rehabil 2015;96:1866-72.

21. O'Neil KH, Purdy M, Falk J, Gallo L. The dysphagia outcome and severity scale. Dysphagia 1999;14:13945. 